\title{
NILAI KEARIFAN LOKAL BUGIS MAKASSAR DALAM CERPEN PANGGIL AKU AISYAH KARYA THAMRIN PAELORI
}

\author{
Sitti Aida Azis \\ Pendidikan bahasa Indonesia, FKIP Universitas Muhammadiyah Makassar \\ Email: bunda.ipass@gmail.com
}

\begin{abstract}
Abstrak
Tujuan penelitian untuk mendeskripsikan nilai-nilai kearifan lokal cerpen "Panggil Aku Aisyah" Karya Thamrin Paelori. Penelitian ini berbentuk deskriptif kualitatif yaitu memaparkan dan menyampaikan data secara objektif nilai-nilai kearifan lokal. Data dalam penelitian adalah: saling menghargai (sipakatau), saling mengingatkan (sipakainge), saling menghargai (sipakalebbi). Sumber data adalah cerpen "Panggil Aku Aisyah" karya Thamrin Paelori, cetakan pertama. Berdasarkan hasil penelitian terungkap bahwa, saling menghargai (sipakatau), merupakan sifat memanusiaakan manusia, yaitu memandang manusia tidak dari segi budaya, ras, agama dan status sosialnya, saling mengingatkan (Sipakainge), merupakan sifat saling mengingatkan. Terlahir sebagai manusia berarti tidak terlepas dari sebuah kesalahan dan kekhilafan.dengan begitu, manusia seharusnya saling mengingatkan karena tidak ada manusia yang terlahir sempurna walau manusia adalah ciptaan Tuhan yang paling sempurna dan kekurangan itulah yang akan menyempurnakan manusia. Saling menghargai (Sipakalebbi), mengingatkan bahwa manusia penuh kekurangan dan kelebihan, serta membutuhkan orang lain, oleh karena itu, apabila ada kekurangn janganlah menjadi ukuran dan tetaplah memandang bahwa manusia pun ada kelebihan
\end{abstract}

Kata kunci: kearifan, lokal, Bugis, Makassar, cerpen

\begin{abstract}
The purpose of research is to describe the values of local wisdom short story "Panggil Aku Aisyah" written by Thamrin Paelori. This research is in the form of qualitative descriptive that is expose and submit data objectively the values of local wisdom. The data in the study are: mutual respect (sipakatau), reminding each other (sipakainge), mutual respect (sipakalebbi). The data source is short story "Panggil Aku Aisyah" by Thamrin Paelori, first print. Based on the research results revealed that, respect for each other (sipakatau), is the human nature, which is looking at human beings not in terms of culture, race, religion and social status, remind each other (Sipakainge), is a mutual nature remind. Born as a human being is inseparable from a mistake and an oversight. Thus human beings should remind each other that no human being is perfectly born even though man is God's most perfect and deficient creation that will perfect man. Mutual respect (Sipakalebbi), reminds that humans are full of deficiencies and advantages, and need others, therefore, if there deficiency not be a measure and still see that humans there are advantages
\end{abstract}

Keywords: wisdom, local, Bugis, Makassar, short story 


\section{PENDAHULUAN}

Kearifan lokal merupakan tata nilai atau perilaku hidup masyarakat lokal dalam berinteraksi dengan lingkungan tempatnya hidup secara arif. Di sisi lain, kearifan lokal merupakan semua bentuk pengetahuan, keyakinan, pemahaman atau wawasan, serta adat kebiasaan atau etika yang menuntun perilaku manusia dalam kehidupan di dalam komunitas ekologis.

Bentuk-bentuk Kearifan lokal yang ada dalam masyarakat dapat berupa nilai, norma, kepercayaan atau aturan-aturan khusus. Dengan begitu, menyebabkan fungsi Kearifan lokal antar lain, sebagai pengembang kebudayaan dan ilmu pengetahuan. Dan sebagai petuah, kepercayaan, sastra, serta pantangan.

Nilai kearifan lokal dalam sebuah karya sastra seringkali tidak terlalu diperhatikan padahal kearifan lokal sangat identik dengan kesusatraan, misalnya tentang kearifan lokal yang bersifat bahasa, panggilan seseorang, dan status sosial. Arif berarti bijaksana, akan tetapi sebagian dari budaya tidak tercermin kearifan. Tindakan merusak alam, dan pemborosan kerap menjadi ritual kebudayaan. Kadang pula berada dalam suatu kebimbangan karena budaya kerap menjadi hal yang sangat sensitif, karena dapat memecah belah persaudaraan. Budaya adalah lekat pada bidang-bidang lain yang terstruktur rapi. Keterkaitan antar unsur kehidupan itulah yang membentuk sebuah budaya. Dengan demikian, budaya bukan sekedar tumpukan acak fenomena, atau bukan sekedar kebiasaan lazim, malainkan tertata rapi dan penuh makna. (Endarswara, 2003 : 1).

Dalam kebudayaan Bugis Makassar ada sesuatu yang sangat urgen dalam kehidupan yaitu siri. Makna siri adalah berbeda-beda menurut ruang dan waktu tertentu tergantung pada bagaimana tingkat perkembangan makna, nilai dan struktur sosil yang mendukungnya atau dengan kata lain, bahwa makna itu sangat ditentukan oleh tingkat kebudayaan yang menyangkut masalah nilai dalam kehidupan. Oleh karenanya, ungkapan-ungkapan yang dapat dikemukakan dapat menjadi jembatan penghubung antara nilai sosial dan nilai budaya yang ada ditengah masyarakat. Seperti tiga sifat yang bisa menjadi pedoman dalam kehidupan sosial masyarakat Bugis Makassar. Ketiga sifat yang dimaksud yaitu sipakatau', sipakainge', dan sipakalebbi .

Ketiga sifat yang diwariskan nenek moyang suku Bugis Makassar tercermin dalam cerpen Panggil Aku Aisyah (selanjutnya disingkat PAA) karya Thamrin Paelori, sebagai kajian dalam penelitian ini, karena fenomena yang terjadi sekarang sudah berkurangnya pengaplikasian penggunaan kearifan lokal tersebut, semakin berkembangnya teknologi yang seakan mengikis sedikit demi sedikit dan mulai dilupakan masyarakat, khususnya generasi muda yang akan menjadi penerus tongkat estefet kehidupan. Dari hasil analisis cerpen PAA pembaca dapat mengetahui nilai-nilai dan kembali menumbuhkan cinta pengaplikasian kearifan lokal yang ada di Sulawesi Selatan, khususnya masyarakat Bugis Makassar.

\section{METODE}

Dirancang berdasarkan deskriptif, agensi operasional fokus pada saling menghargai (sipakatau), saling mengingtkan (sipakaingek), dan saling menghargai (sipakalebbi). Teknik pengumpulan data, yaitu primer dan skunder. Analisis data mengutip bagianbagian isi cerita yang menunjukkan kebenaran analisis, dengan demikian setiap nilai kearifan lokal yang dikemukakan dilengkapi dengan kutipan yang menunjukkan kebenaran analisis. 


\section{PEMBAHASAN}

Hasil analisis data dalam penelitian ini sebagaimana uraian berikut.

\section{Saling Menghargai atau Sipakatau}

Etnis Bugis dan etnis Makassar adalah dua di antara empat etnis besar yang berada di Sulawesi Selatan. Pada hakekatnya kebudayaan dan pandangan hidup orang Bugis pada umumnya sama dengan pandangan hidup orang Makassar. Oleh karena itu, membahas tentang budaya Bugis sulit dilepaskan dengan pembahasan tentang budaya Makassar. Hal ini sejalan dengan pandangan Abdullah (1985) bahwa dalam sistem keluarga atau dalam kekerabatan kehidupan manusia Bugis dan manusia Makassar, dapat dikatakan hampir tidak terdapat perbedaan.

Di dalam kehidupan masyarakat Bugis Makassar sipakatau adalah nilai sosial yang membentuk kearifan lokal (local wisdom) dan telah dianut serta menjadi bagian dari kehidupan sehari-hari. Saling menghargai adalah konsep yang memandang setiap manusia sebagai manusia. Sipakatau yang bermakna saling menghargai sebagai individu yang bermartabat. Nilai-nilai Sipakatau menunjukkan bahwa budaya Bugis-Makassar memposisi-kan manusia sebagai makhluk ciptaan Allah yang mulia dan oleh karenanya harus dihargai dan diperlakukan secara baik.

Konsep saling menghargai atau sipakatau dalam cerpen PAA dapat dilihat uraian berikut.

[...] "Istirahatlah Daeng, sudah larut malam, nanti besok Bisa dilanjutkan," Indo Upe memecah kesunyian tatkala melihat suaminya terus terbenam dalam kenikmatannya. Peringatan itu sudah sangat dihafal oleh Daeng Sallo. [...] "Aku paham, Upe. Ini semua untuk Latuwo, bukan untuk orang lain. Untuk anak kita. “ Daeng Sallo kembali membangkitkan rasa rindu pada kedua anaknya. (Paelori, hlm. 7).

[...],Indo Upe menatap suaminya dengan lekat. Daeng Sallo

Tersenyum getir.

"Perangkap torisalo itu ? Tanya Daeng Sallo sambil mengerutkan dahi. Diletakkannya gelas yang telah kosong di dekatnya. [...]Indo Upe hanya mengangguk lemah tanpa berani melihat wajah suaminya menegang dengan tatapan kosong.

“ Mengapa aku yang dituduh?” suara Daeng Sallo seolah diperdengarkan kepada angin yang ada disekelilingnya.

"Entahlah, Daeng. Kata mereka kita selalu menghalangi niatnya untuk menangkap torisalo, penunggu sungai itu, $[\ldots]$ Indo Upe berucap dengan hati-hati dan selembut mungkin. (Paelori, hlm. 9).

[...]"Jalanmi Daeng " Aku mengajak pak supir yang berdiri di sisi mobil.

[...]"Belumpi penuh Kareng" jawabnya disertai dengan senyum. Aku menoleh. Masih kurang tiga orang. Biasanya mobil meninggalkan terminal jika penumpang sudah penuh.

[...]"Saya pi yang bayar untuk empat orang Daeng". Aku sudah tidak sabaran. Bayangan ibu, ayah, saudara dan segenap kawan kecilku telah terlintas di depan mata. (Rahim, hlm. 19).

[...]"Dari mana dik?" tanyanya dengan sopan disertai dengan senyum yang ramah.

"Sekolah," jawabku sekenanya.

Setelah itu, diam. Ia juga tidak berbicara banyak. (2)Tapi dalam diam, setiap sekali matanya membentur bola mataku pasti ia tersenyum ramah. Ramah sekali. (Paelori, hlm. 56).

[...]"Terima kasih, Dik, " katanya dengan cepat melihat keherananku. "Itu rasa syukur saya, berkat pertolongan adik, 
ibu saya sembuh," sambungnya lagi sembari tersenyum ramah. (Paelori, hlm. 60).

Berdasarkan kutipan-kutipan tersebut, memperlihatkan keluarga harmonis saling menghargai antara suami dan isteri yang ditandai berbicara sopan, lemah lembut antara Indo Upe dan Daeng Sallo. Kutipan tersebut pun, menggambarkan perbincangan yang sopan antara Daeng Sallo dan Indo Upe., percakapan tersebut sangat relefan dengan nilai sipakatu karena seperti yang telah dipaparkan dalam bab sebelumnya siapakatau adalah sifat memanusiakan manusia. Daeng Sallo dan Indo Upe menggunakan bahasa yang sopan dan saling menghargai antara suami istri seperti bagaimana mestinya.

Bahasa yang digunakan tokoh dalam cerpen PAA, menunjukkan ciri dari pribadi tokoh menjunjung etika dan kelembutan. Benarlah ungkapan yang menyatakan bahwa mampu bertutur kata secara halus dan isi tuturan memiliki maksud jelas dapat menyejukkan hati dan membuat orang lain berkenan, hal demikian merupakan dambaan setiap orang. Seandainya perilaku bahasa setiap orang seperti itu, rasa kebencian, rasa curiga, sikap berperasangka buruk terhadap orang lain tidak perlu ada. Dengan demikian, hubungan antar-manusia akan penuh dengan kebahagiaan, dan hidup manusia akan penuh dengan kesejahteraan.

Kelembutan dalam berbahasa memiliki pengaruh mendalam, bukan hanya sekedar sampainya informasi. Tetapi terjadi perubahan pandangan, sikap, sebagaimana suami istri dalam cerpen tersebut tercermin kesantunan berbahasa dari pembicara dengan orang yang diajak berbicara. Dan jelaslah, bahwa kelembutan dapat membalikkan hati gundah, takut/cemas menjadi tenang dan riang. Lupa akan kesulitannya kekhawatiran, gundah,karena berbicara lembut sebagai dalamnya cinta antara suami dan istri. $\begin{array}{rrr}\text { Dengan } & \text { begitu, } & \begin{array}{r}\text { budaya } \\ \text { sipakatau }\end{array} \\ \text { menghargai } & \text { atau }\end{array}$ diwujudkan melalui bahasa, sikap, dan contoh perilaku dari masyarakat yang merupakan cerminan kahidupan masyarakat tersebut (Bugis Makassar).

\section{Saling Mengingatkan atau Sipakaingek}

Saling mengingatkan atau sipakainge sangat erat hubungannya dengan watak yaitu sifat batin manusia yang mempengaruhi segenap pikiran dan perbuatannya. Saling mengingatkan dalam cerpen PAA karya Paleori antara lain , saling mengingatkan tidak mengganggu, tidak memusuhi, tidak membunuh, kendati orang yang dimaksud telah berbuat salah yaitu ber-utang kepada banyak orang. Untuk lebih jelasnya diperhatikan uraian berikut ini.

[...] Jangan ganggu..., Jangan ganggu dia! Anakku tidak bersalah. Dia tidak bersalah...! Daeng Sallo berteriak dengan mata tajam menancap satupersatu orang di sekelilingnya. (Paelori, hlm. 12).

[...]Torisalo yang kamu musuhi itu adalah anakku. Adalah darah dagingku. Jika kamu membunuhnya, berarti kamu juga telah membunuhku...!!!" suara Daeng Sallo semakin meninggi dengan matanya tetap jalang meneliti orang-perorang yang mengelilinya. (Paelori, hlm. 12).

[...] Dia telah mengambil uang dengan meminjam kepada warga di sini. Hampir seluruh warga telah diutangi. Dan kini dia sudah kabur entah ke mana," jelas pemuda itu, yang juga katanya ia termasuk korbannya. (Paelori, hlm. 62).

Kutipan tersebut, memperjelas pentingnya saling mengingatkan atau 
sipakaingek untuk terciptanya saling menghargai antara satu dengan yang lainnya. Sehingga pembunuhan tidak terjadi (ketika Daeng Sallo mengingatkan kepada penduduk agar tidak membunuh Torisalo yang dianggap anaknya). Kendati masyarakat marah dan membenci kepada Torisalo karena seluruh warga telah diutangi, sementara dia (Torisalo) telah melarikan diri entah ke mana.

Berkaitan dengan kutipan tersebut, sedapat mungkin ditanamkan etika bergaul, karena bergaul sangat berpengaruh dalam membentuk kerukunan dan kedamaian dalam toleransi, karena manusia adalah makhluk sosial yang selalu berhubungan dan saling membutuhkan satu sama lain, setiap orang memiliki kekurangan dan kelebihan serta memerlukan bantuan orang lain. Oleh karena itu, dalam bergaul harus bertingkah laku sopan santun (penyantunan), lemah lembut dan tidak bertindak salah (keliru). Dapat membedakan yang baik dan buruk seperti halnya bagaimana menghadapi berita khayal (kosong) yang dibawa dan disebarkan oleh orang fasik dan jail. Cara menyelesaikan persengketaan antar-sesama yang timbul di kalangan umat yaitu dengan bersatu padu dalam satu tujuan melawan kejahilan, karena pada dasarnya sesama manusia bersaudara.

Di samping itu, perlu pula ditanamkan etika berperilaku yakni tindakan-tindakan manusia yang dilakukan dengan sengaja, tidak melampaui batas kodratnya, ialah kemanusiaannya. Namun di dalam kehidupan bermasyarakat, sering ditemui perilaku-perilaku individual maupun kelompok yang menyimpang dari normanorma yang berlaku di dalam masyarakat tersebut. Manusia menurut Asyillah (2007) dan Baurke (1966) sebagai individu secara sadar maupun tidak sadar pernah melakukan perilaku menyimpang atau penyimpangan sosial. Dari penyimpangan sosial yang ada, maka hal tersebut akan mengakibatkan terganggunya keseimbagan hidup bermasyarakat.

Ketidak terjadinya peraktik pembunuhan sebagaimana kutipan tersebut karena adanya budaya sipakaingak oleh Daeng Sallo, sehingga mengingatkan jangan ada pembunuhan kendati salah yaitu terjadi keributan, saling caci maki akibat perbuatan satu orang (Paleori) ber-utang kebanyak orang sehingga tidak sanggup membayar akhirnya kabur.

Dengan begitu, saling mengingatkan atau sipakainge hadir sebagai penuntun bagi masyarakat Bugis Makassar sebagai bukti bahwa manusia adalah individu yang tidak lepas dari kekurangan dan kesalahan. Sipakainge yang berarti saling mengingatkan merupakan salah satu upaya pencegahan agar manusia terhindar dari perbuatan yang melanggar norma-norma yang telah ditetapkan

\section{Saling Menghargai atau Sipakalebbi}

Saling menghargai atau sipakalebbi identik dengan puji-pujian, yang berarti sesama manusia senantiasa saling memuji satu sama lain dan saling menghargai demi menjaga keharmonisan kehidupan seharihari. Manusia biasa tidak dapat dipisahkan dengan hati nurani, yang senantiasa menyenangi segala hal yang berbau dengan keindahan baik berupa barang hingga katakata atau pujian. Mengakui kelebihan orang lain serta kekurangan diri sendiri, dan menerima semua keadaan itu dengan hati yang terbuka serta saling menutupi kekurangan masing-masing atau saling bahu membahu dalam segala kegiatan merupakan bentuk penghargaan terhadap satu sama lain (Razak, 2015).

Saling menghargai atau sipakalebbi dalam cerpen PAA, dapat dilihat uraian berikut ini.

[...] Latuwo kan paling suka daging burung belibis. [...] Mumpung aku masih hidup. Kalau bukan aku, siapa lagi yang akan mengangkap belibis 
untuk anak kita ?" Daeng Sallo bercerita dengan nada sendu bercampur. Kadang-kadang berhenti sejenak. Meluruskan punggungnya yang sudah mulai sakit ketika duduk lama. (Paelori, hlm. 7).

[...] "Bukan anakku, bukan!" Daeng Sallo membela anaknya. (Paelori, hlm. 13).

[...] "kemarin saya dapat telegram dari adik, dia diminta dikirimi uang untuk biaya pengobatan itu." Tuturnya tanpa aku minta, tatkala aku sempat terdiam bebererapa jenak.

[...]Aku agak terenyuh dengan penuturannya. [...] Naluri

kemanusiaanku tak embantah sedikitpun. Aku menganngguk.

(Paelori, hlm. 59).

\begin{tabular}{llr}
\multicolumn{2}{c}{ Kutipan tersebut } & \multicolumn{2}{r}{ memperlihatkan } \\
bahwa, Daeng & Sallo & sangat \\
memperjuangkan & dan & ingin
\end{tabular}
membahagiakan anaknya walaupun anaknya yang diyakininya itu adalah seekor buaya. Rela berburu kendati kondisi tubuhnya yang sakit-sakitan demi anaknya yang suka daging belibis. Di sisi lain, Daeng Sallo rela mati membela seekor buaya yang diyakini bahwa buaya itu adalah darah dagingnya yang pada saat itu akan dibunuh warga. Demikian pula, sipakalebbi terlihat merupakan sifat yang tidak melihat manusia dari kekurangannya dan terlihat jelas dari kutipan tersebut, ketika bersedia menolong orang lain yang sedang kesusahan walaupun orang itu belum tertalu dikenalnya.

Makhluk yang berwujud manusia, senantiasa mengharap orang lain mengasihinya. Orang akan menjadi bahagia kalau disayangi, sebaliknya orang itu akan menjadi hampa dan kekosongan jiwanya kalau tidak ada orang yang mengasihinya. Anak-anak disayangi oleh ibu bapak, dan ibu bapak disayangi oleh anak-anak. Dengan demikian, akan terwujudlah dalam satu rumah, orang tua sayang pada anak-anak dan anak-anak sayang pada orang tua.

Dengan demikian, kasih sayang dan perhatian orang tua terhadap anaknya merupakan hal terpenting dalam sebuah keluarga. Tanpa adanya kasih sayang dan perhatian dari orang tua, seorang anak tidak akan pernah merasa nyaman berada di rumah. Bukan itu saja, dampak terparah yang dapat timbul adalah anak tersebut tidak akan pernah lagi ingin berada di rumah, anak itu ingin mencari kehidupan lain di luar rumah. Hal itu tentu saja dapat mengubah kepribadian anak, bahkan anak dapat terjerumus ke pergaulan salah yang akan membawanya ke dalam jurang kehancuran.

\section{KESIMPULAN}

Sastra, di samping sebagai hiburan yang bermanfaat dan menyenangkan, pun berfungsi menyikap rahasia terhadap manusia, memberikan makna terhadap eksistensi manusia dan membuka jalan kepada kebenaran dengan memperhatikan nilai-nilai kearifan lokal.

Nilai kearifan lokal yang dimaksud di sini adalah nilai sipakatau, sipakainge dan sipakalebbi yang terpendam dalam cerpen Panggil Aku Aisyah karya Thamrin Paelori

\section{DAFTAR PUSTAKA}

Abdullah, Taufik dan A.C. van der Leeden (ed)1986. Durkheim dan Pengantar Sosiologi Moralitas. Jakarta: Yayasan Obor Indonesia.

Asyillah. 2007. "Etika". Tanggal 09

Februari 2018, dalam www.asyilla.wordpress.com

Baurke, V.J,. 1966, Ethies A Texbook in Moral Philoshopy. New York: The Macmillan Company. 
Endarswara, Suwardi Metodologi Penelitian Kebudayaan. Yogyakarta : Gadjah Mada University Press

Keraf, a.Soni. 2010. Etika Lingkungan Hidup. Jakarta: Buku Kompas.

Mattulada, 1998. Kebudayaan, Kemanusiaan dan Lingkungan Hidup.
Makassar: Hasanuddin University Press

Supriatna, Jatna. tt. "Peranan Kearifan Lokal dan Ilmu-ilmu Kepribumian dalam Pelestarian Alam." 9 Februari 2018 dalam forumprbbogor.org/arsip/dokumen. 